\title{
Mechanical ventilation and the daily cost of ICU care
}

Klaus Kaier ${ }^{1 *}$, Thomas Heister ${ }^{1}$, Jan Wolff ${ }^{2,3}$ and Martin Wolkewitz ${ }^{1}$

\begin{abstract}
Background: Intensive care units represent one of the largest clinical cost centers in hospitals. Mechanical ventilation accounts for a significant share of this cost. There is a relative dearth of information quantifying the impact of ventilation on daily ICU cost. We thus determine daily costs of ICU care, incremental cost of mechanical ventilation per ICU day, and further differentiate cost by underlying diseases.

Methods: Total ICU costs, length of ICU stay, and duration of mechanical ventilation of all 10,637 adult patients treated in ICUs at a German hospital in 2013 were analyzed for never-ventilated patients $(N=9181)$, patients ventilated at least 1 day, $(N=1455)$ and all patients $(N=10,637)$. Total ICU costs were regressed on the number of ICU days. Finally, costs were analyzed separately by ICD-10 chapter of main diagnosis.

Results: Daily non-ventilated costs were €999 (95\%Cl €924 - €1074), and ventilated costs were €1590 (95\%Cl €1524 - €1657), a 59\% increase. Costs per non-ventilated ICU day differed substantially and were lowest for endocrine, nutritional or metabolic diseases (€844), and highest for musculoskeletal diseases (€1357). Costs per ventilated ICU day were lowest for diseases of the circulatory system (€1439) and highest for cancer patients (€1594). The relative cost increase due to ventilation was highest for diseases of the respiratory system (94\%) and even non-systematic for patients with musculoskeletal diseases $(13 \%, p=0.634)$.
\end{abstract}

Conclusions: Results show substantial variability of ICU costs for different underlying diseases and underline mechanical ventilation as an important driver of ICU costs.

Keywords: Mechanical ventilation, Critical care, Daily cost, ICD-10

\section{Background}

Intensive care units (ICUs) represent one of the largest clinical cost centers in hospitals [1]. Mechanical ventilation (MV) accounts for a significant share of this cost [2]. Patients requiring MV represent a substantial share of all ICU patients and have been shown to account for a disproportionately high share of total ICU costs [2-5]. Intensive care patients require therapy that varies considerably in type, duration, and cost. Despite the need for detailed cost data to inform policy makers, there is a

\footnotetext{
*Correspondence: kaier@imbi.uni-freiburg.de

${ }^{1}$ Institute for Medical Biometry and Statistics, Faculty of Medicine and

Medical Center, University of Freiburg, Stefan-Meier-Straße 26, 79104 Freiburg, Germany

Full list of author information is available at the end of the article
}

relative dearth of information relating to the daily cost of ICU care for different patient groups and the impact of MV on these costs [2]. Therefore, the objectives of this analysis is to determine the daily costs of ICU care, the incremental cost of MV per ICU day, and to further differentiate these cost figures for patients with different underlying diseases. This, we argue, is an important step towards a better understanding of resource utilization in hospitals and quantifying the burden of diseases requiring intensive care treatment.

\section{Methods}

We collected total ICU costs, length of ICU stay, and duration of mechanical ventilation of all 10,637 patients aged 18 years or older treated in ICUs at the University

(c) The Author(s). 2020 Open Access This article is licensed under a Creative Commons Attribution 4.0 International License, which permits use, sharing, adaptation, distribution and reproduction in any medium or format, as long as you give appropriate credit to the original author(s) and the source, provide a link to the Creative Commons licence, and indicate if changes were made. The images or other third party material in this article are included in the article's Creative Commons licence, unless indicated otherwise in a credit line to the material. If material is not included in the article's Creative Commons licence and your intended use is not permitted by statutory regulation or exceeds the permitted use, you will need to obtain permission directly from the copyright holder. To view a copy of this licence, visit http://creativecommons.org/licenses/by/4.0/. The Creative Commons Public Domain Dedication waiver (http://creativecommons.org/publicdomain/zero/1.0/) applies to the data made available in this article, unless otherwise stated in a credit line to the data. 
Medical Center Freiburg (UMCF) in 2013. The UMCF is a tertiary care teaching hospital in southern Germany.

Cost figures were calculated using the widely used bottom up microcosting approach according to the standardized methods of the Institute for the Payment system in Hospitals (InEK), which is the German calculation authority responsible for reimbursement rates [6-8]. This de facto accounting standard not only allows the calculation of reimbursement rates for each G-DRG, but it is also suitable for strategic planning and benchmarking, and, due to its accuracy and transparency, for cost analysis [7]. Briefly, according to the InEK handbook of calculation the cost object accounting is based on a defined cost template and corresponding cost categories [9]. Costs are divided into three main categories: [1] staff costs, [2] material costs and [3] infrastructure costs. Within the three categories, a total of 11 different cost centers are calculated (see Additional file 1). Cost allocation on each inpatient case generates a uniform cost-matrix and relies on a full cost approach using real costs. Direct costs, which are mandatory for implants, blood products or drugs etc., are based on the documented utilization. Overhead costs and costs on primary cost units are charged based upon key cost drivers. Amounts for indirect cost units such as on demand medication or dressing material are allocated to primary cost units and are excluded if they are not relevant for the corresponding G-DRG [7, 9]. Labor costs, which are crucial in ICU settings, are measured according to actual utilization of the respective caregiver (medical staff, nursing staff, and technical staff; see Additional file 1). Daily ICU costs were not available for analysis. Instead, we analyzed total ICU costs within three different groups of ICU patients: never-ventilated ICU patients $(N=9181)$, ICU patients ventilated at least 1 day, $(N=1455)$ and all ICU patients $(N=10,637)$. We used linear regression models, regressing total ICU costs on the number of ICU days. For the second and third group we additionally regressed on the number of ventilation days. This way we estimate and compare the daily costs of ICU stay between the three groups in order to determine whether estimated costs of a single nonventilated ICU day are different between never-ventilated patients and patients that are ventilated at some point in their ICU stay. Finally, we differentiated our estimation for the patients' underlying diseases by repeating the above described analyses for subgroups of patients of each ICD-10 chapter separately, using the patients' main diagnosis (the main reason for hospitalization). All results regarding the impact of ventilation on daily ICU cost were shown on an absolute and relative scale. For all statistical analyses Stata Version 15.1 (Stata Corp, College Station, Texas, USA) is used.

\section{Results}

In 2013, 10,636 patients were treated in ICUs at UMCF. Of these patients, a total of 1455 (14\%) received mechanical ventilation. As shown in Table 1, daily costs of non-ventilated ICU care were $€ 999$ (95\%CI $€ 924$ $€ 1074)$, and daily costs per ventilated ICU day were $€ 1590$ (95\%CI €1524 - €1657). The cost per nonventilated ICU day is similar between those neverventilated and patients ventilated at some point during their hospital stay. This suggests that the higher total daily costs of ventilated patients may be attributed to the costs of ventilation rather than the underlying disease. While the higher costs of mechanical ventilation can in part be a reflection of the costs calculation method, one would expect the underlying disease to be responsible for a large part of the cost. For different underlying diseases the share of patients receiving mechanical ventilation varies widely: $41 \%$ of all ICU patients with infectious or parasitic diseases (ICD-10 Chapter I) were ventilated, but (almost) no patients with eye or ear related diseases or pregnancy were ventilated (see Table 1). Estimated costs per ventilated ICU day were lowest for patients with diseases of the circulatory system (€1439) and highest for cancer patients $(€ 1594)$. In contrast, costs per nonventilated ICU day differed substantially and were lowest for patients with endocrine, nutritional or metabolic diseases (€844), and highest for patients with musculoskeletal diseases $(€ 1357)$. Average cost increase due to mechanical ventilation was 59\% (95\%CI 53-66\%) (Fig. 1). The cost increase due to ventilation was highest for patients hospitalized due to diseases of the respiratory system (94\%), and even non-systematic for patients with musculoskeletal diseases $(13 \%, p=0.634)$.

\section{Discussion}

Intensive care is a major cost component in modern healthcare systems [10]. In our sample, initiation of mechanical ventilation led to a $59 \%$ average cost increase, a very considerable increase. While costs of a ventilated ICU day differed very little between the different patient groups, the large variability of the cost increase associated with initiation of ventilation could open up avenues to effective resource allocation by for example focusing preventative measures, where multiple possible interventions might compete for funding, on the patient groups where avoidance of MV would be associated with the highest savings. Detailed cost data is thus useful to inform policy and optimally allocate limited resources. Our findings contribute towards this.

Overall, our results are in line with the available literature [2-5]: Dasta et al. (2005), for instance found much higher daily costs of a non-ventilated or ventilated bed day at US hospitals (US\$3250 and US\$4772, in 2002 values), but the relative cost increase (47\%) seems comparable [2]. Other studies reported much lower extra costs of mechanical ventilation: Moran et al. (2004) determined the daily costs of a non-ventilated or ventilated 
Table 1 Descriptive statistics

\begin{tabular}{|c|c|c|c|}
\hline & $\begin{array}{l}\text { Cost per non-ventilated ICU day } \\
{[95 \% \mathrm{CI}]}\end{array}$ & $\begin{array}{l}\text { Cost per ventilated ICU day } \\
{[95 \% \mathrm{CI}]}\end{array}$ & $\begin{array}{l}\text { Number of patients that were ventilated } \\
\mathrm{N}, \%\end{array}$ \\
\hline $\begin{array}{l}\text { Never-ventilated ICU } \\
\text { patients }\end{array}$ & $961 €$ & & $0,0 \%$ \\
\hline$N=9181$ & {$[926 €-993 €]$} & & \\
\hline Ventilated ICU patients & $1062 €$ & $1617 €$ & $1455,100 \%$ \\
\hline$N=1455$ & {$[870 €-1253 €]$} & {$[1504 €-1730 €]$} & \\
\hline All ICU patients & $999 €$ & $1590 €$ & $1455,14 \%$ \\
\hline$N=10,636$ & {$[924 €-1074 €]$} & {$[1524 €-1657 €]$} & \\
\hline I infectious and parasitic & $864 €$ & $1561 €$ & $98,41 \%$ \\
\hline$N=239$ & {$[833 €-894 €]$} & {$[1521 €-1601 €]$} & \\
\hline II Neoplasms & $1002 €$ & $1594 €$ & $184,6 \%$ \\
\hline$N=2938$ & {$[959 €-1044 €]$} & {$[1542 €-1646 €]$} & \\
\hline IV Endocrine & $844 €$ & $1575 €$ & $18,5 \%$ \\
\hline$N=370$ & {$[804 €-883 €]$} & {$[1512 €-1638 €]$} & \\
\hline VI nervous system & $908 €$ & $1477 €$ & $53,12 \%$ \\
\hline$N=427$ & {$[882 €-935 €]$} & {$[1441 €-1513 €]$} & \\
\hline VII Diseases of the eye & $845 €$ & & $1,0.3 \%$ \\
\hline$N=344$ & {$[838 €-851 €]$} & & \\
\hline VIII Diseases of the ear & $846 €$ & & $1,1 \%$ \\
\hline$N=101$ & {$[836 €-856 €]$} & & \\
\hline IX Circulatory & $929 €$ & $1439 €$ & $387,30 \%$ \\
\hline$N=1304$ & {$[918 €-940 €]$} & {$[1427 €-1427 €]$} & \\
\hline $\mathrm{X}$ respiratory & $795 €$ & $1539 €$ & $247,31 \%$ \\
\hline$N=792$ & {$[759 €-831 €]$} & {$[1512 €-1565 €$} & \\
\hline $\mathrm{XI}$ digestive & $920 €$ & $1517 €$ & $124,18 \%$ \\
\hline$N=700$ & {$[904 €-936 €]$} & {$[1496 €-1538 €]$} & \\
\hline XIII muscoskeletal & $1357 €$ & $1537 €$ & $36,6 \%$ \\
\hline$N=592$ & {$[628 €-2087 €]$} & {$[1439 €-1636 €]$} & \\
\hline XIV genitourinary & $857 €$ & $1524 €$ & $14,5 \%$ \\
\hline$N=276$ & {$[854 €-861 €]$} & {$[1512 €-1536 €]$} & \\
\hline XV Pregnancy & $597 €$ & & $1,0.2 \%$ \\
\hline$N=659$ & {$[495 €-699 €]$} & & \\
\hline $\begin{array}{l}\text { XVIII not elsewhere } \\
\text { classified }\end{array}$ & $847 €$ & $1531 €$ & $22,12 \%$ \\
\hline$N=191$ & {$[819 €-875 €]$} & {$[1444 €-1619 €]$} & \\
\hline XIX Injury, poisoning & $1002 €$ & $1498 €$ & $249,18 \%$ \\
\hline$N=1363$ & {$[909 €-1094 €]$} & {$[1451 €-1546 €$} & \\
\hline XXI Factors influencing & $857 €$ & & $0,0 \%$ \\
\hline$N=116$ & {$[854 €-860 €]$} & & \\
\hline
\end{tabular}

Note: Subgroups of patients with identical ICD-10 chapters but $N<100$ were not analyzed. In subgroups where less than 2 patients were ventilated, costs per ventilated ICU day are not shown

bed day at Australian hospitals (AU\$1616 and AU\$1911, in 1991 values), corresponding to a relative cost increase of $18 \%$ [3]. The only other German study on the topic found costs of a non-ventilated or ventilated bed day of
EUR 680 and EUR 946 (in 2003 values), a relative cost increase of $39 \%$ [1].

One surprising finding was that ICU patients with musculoskeletal diseases (as main diagnosis) were, on 


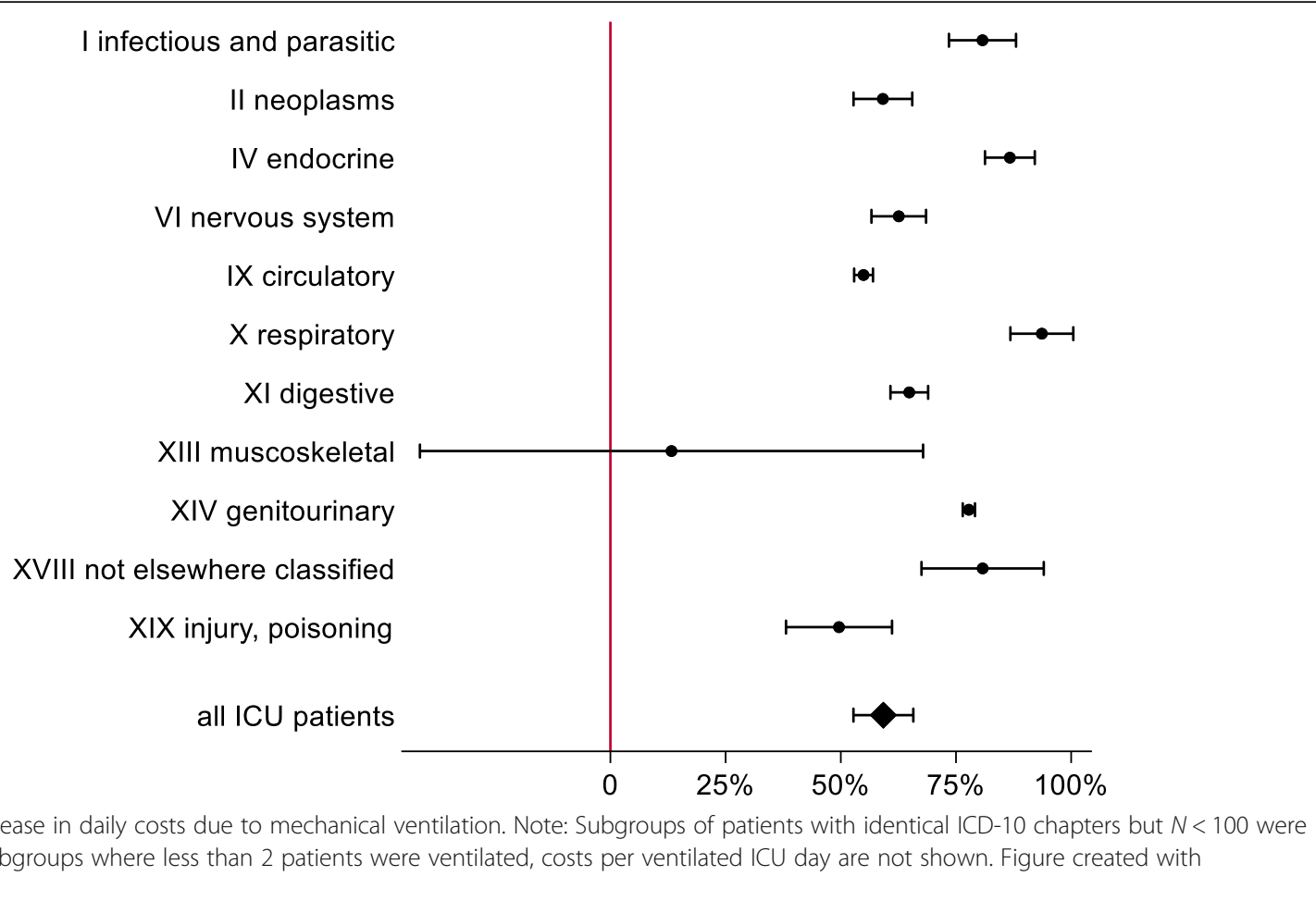

average, associated with very high daily costs even when not ventilated ( $€$ 1357). This was especially marked when compared to ICU patients with respiratory diseases, who were associated with much lower daily costs when not ventilated (€ 795). This may imply that ICU patients with musculoskeletal diseases, on average, require higher treatment intensity even when they are not ventilated. Among the ICU patients with respiratory diseases (as main diagnosis), in contrast, the absence of ventilation might be associated with a generally lower treatment intensity.

A limitation of our study of course is the single-center nature of the data, however the sample was decently-sized and included all patients treated in the period examined, limiting some sources of bias. The competing interests of the hospital to trigger reimbursement for services rendered and the sickness funds to limit cost should result in a good level of reliability of the administrative data.

Another limitation is that daily ICU costs were not available for analysis. In practice, avoidance of one last additional day of ventilation in a given patient is expected to lead to lower cost savings than avoidance of the most expensive first day of ventilation, after which daily cost drops rapidly [2]. However, this does not detract from the usefulness of our findings on the cost differences between patient groups by the ICD10 chapter of the main diagnosis, which has been previously underreported and is important due to the large size of the effect.

\section{Key points for decision makers}

- Mechanical ventilation markedly increases daily ICU cost.

- The magnitude of the increase over unventilated care differs strongly between different underlying diseases.

- It might be possible to generate saving by focusing budgets for efforts to prevent necessity of ventilation on fields where initiation of ventilation would lead to a particularly pronounced cost increase.

\section{Conclusions}

Overall, the results show substantial variability of ICU costs for patients with different underlying diseases and underline mechanical ventilation as an important driver of ICU costs. This needs to be taken into account when estimating the economic burden of diseases that require intensive care treatment with or without mechanical ventilation. More studies on the daily costs of mechanical ventilation and intensive care are duly needed.

\section{Supplementary information}

Supplementary information accompanies this paper at https://doi.org/10 1186/s12913-020-05133-5.

Additional file 1. The cost matrix for every case. Costs are allocated to cases according to the key cost drivers for cost modules shown in the cost-matrix. 


\section{Abbreviations}

EUR: Euros; G-DRG: German diagnosis related groups; ICD-10: International Classification of Diseases, 10th revision; ICU: Intensive care unit; InEK: Institute for the Payment system in Hospitals; MV: Mechanical ventilation; UMCF: University Medical Center Freiburg

\section{Acknowledgements}

Not applicable.

\section{Authors' contributions}

KK contributed to the conceptualization, methodology and formal analysis and wrote the original draft. TH contributed to the investigation, formal analysis and data curation as well as the review and editing of the manuscript. JW contributed to the investigation, formal analysis and data curation as well as the review and editing of the manuscript. MW contributed to the conceptualization, methodology and the review and editing of the manuscript. All authors have read and approved the manuscript.

\section{Funding}

This research project receives support from the Innovative Medicines Initiative Joint Undertaking under grant agreement nº 115523 | 115620 | 115737 resources of which are composed of financial contribution from the European Union Seventh Framework Programme (FP7/2007-2013) and EFPIA companies in kind contribution. The research leading to these results was conducted as part of the COMBACTE-MAGNET consortium. For further information please refer to www.COMBACTE.com

$\mathrm{TH}$ and $\mathrm{MW}$ are recipients of grants from the German Research Foundation (grant no. WO 1746/1-2 to MW and grant no. KA 4199/1-1 to TH). KK has received funds from the Innovative Medicines Initiative Joint Undertaking under grant agreement no. 115737-2 (Combatting bacterial resistance in Europe - molecules against Gram negative infections [COMBACTE-MAGNET]). The funders had no role in the preparation of this manuscript. Publication of study results was not contingent on the sponsor's approval or censorship of the manuscript.

\section{Availability of data and materials}

The data cannot be shared since transfer of the data outside the Medical Center - University of Freiburg network is prohibited under the European Union General Data Protection Regulation (GDPR).

\section{Ethics approval and consent to participate}

Patients provided informed written consent on admission to the use of their pseudonymized data for scientific purposes, in accordance with German data protection law. The use of the data was approved by the University Medical Center Freiburg Ethics Committee.

The study design complies with institutional and national research ethics regulations and has been performed in accordance with the ethical standards as laid down in the 1964 Declaration of Helsinki and its later amendments.

\section{Consent for publication}

Not applicable. The study only included pseudonymized routine data and the researchers were unable to connect data to individual patients.

\section{Competing interests}

The authors declare that they have no competing interests.

\section{Author details}

${ }^{1}$ Institute for Medical Biometry and Statistics, Faculty of Medicine and Medical Center, University of Freiburg, Stefan-Meier-Straße 26, 79104 Freiburg, Germany. ${ }^{2}$ Klinik für Psychiatrie und Psychotherapie Universitätsklinikum Freiburg Medizinische Fakultät Albert-Ludwigs-Universität Freiburg, Freiburg, Germany. ${ }^{3}$ Evangelische Stiftung Neuerkerode, Klostergang 66, 38104 Braunschweig, Germany.
Received: 27 May 2019 Accepted: 20 March 2020

Published online: 31 March 2020

\section{References}

1. Moerer O, Plock E, Mgbor U, Schmid A, Schneider H, Wischnewsky MB, et al. A German national prevalence study on the cost of intensive care: an evaluation from 51 intensive care units. Crit Care. 2007;11(3):R69.

2. Dasta JF, McLaughlin TP, Mody SH, Piech CT. Daily cost of an intensive care unit day: the contribution of mechanical ventilation. Crit Care Med. 2005; 33(6):1266-71.

3. Moran JL, Peisach AR, Solomon PJ, Martin J. Cost calculation and prediction in adult intensive care: a ground-up utilization study. Anaesth Intensive Care. 2004;32(6):787-97.

4. Jacobs P, Rapoport J, Edbrooke D. Economies of scale in British intensive care units and combined intensive care/high dependency units. Intensive Care Med. 2004;30(4):660-4.

5. Kahn JM, Rubenfeld GD, Rohrbach J, Fuchs BD. Cost savings attributable to reductions in intensive care unit length of stay for mechanically ventilated patients. Med Care. 2008:46(12):1226-33.

6. Quentin W, Geissler A, Scheller-Kreinsen D, Busse R. DRG-type hospital payment in Germany: the G-DRG system. Euro Obs. 2010;12(3):4-6.

7. Vogl M. Assessing DRG cost accounting with respect to resource allocation and tariff calculation: the case of Germany. Heal Econ Rev. 2012;2(1):15.

8. Gutmann A, Kaier K, Sorg S, von zur Mühlen C, Siepe M, Moser M, et al. Analysis of the additional costs of clinical complications in patients undergoing transcatheter aortic valve replacement in the German health care system. Int J Cardiol. 2015;179:231-7.

9. Reinöhl J, Gutmann A, Kollum M, von zur Mühlen C, Baumbach H, Avlar M, et al. Transfemoral aortic valve implantation: bleeding events, related costs and outcomes. J Thromb Thrombolysis. 2013;35(4):469-75.

10. Halpern NA, Pastores SM. Critical care medicine in the United States 20002005: an analysis of bed numbers, occupancy rates, payer mix, and costs. Crit Care Med. 2010;38(1):65-71.

\section{Publisher's Note}

Springer Nature remains neutral with regard to jurisdictional claims in published maps and institutional affiliations.
Ready to submit your research? Choose BMC and benefit from:

- fast, convenient online submission

- thorough peer review by experienced researchers in your field

- rapid publication on acceptance

- support for research data, including large and complex data types

- gold Open Access which fosters wider collaboration and increased citations

- maximum visibility for your research: over $100 \mathrm{M}$ website views per year

At BMC, research is always in progress.

Learn more biomedcentral.com/submission 